\title{
Bicornuate Uterus: Infertility Treatment and Pregnancy Continuation without Cerclage: An Unusual Case
}

\author{
Meenal Parmar, Surabhi Tomar \\ Department of Obstetrics and Gynaecology, Nims Medical College and Hospital, Jaipur, India \\ Email: drmeennalparmar@gmail.com
}

Received 28 August 2014; revised 25 September 2014; accepted 20 October 2014

Academic Editor: Wadhwa Leena, ESI-PGIMSR, India

Copyright (C) 2014 by authors and Scientific Research Publishing Inc.

This work is licensed under the Creative Commons Attribution International License (CC BY). http://creativecommons.org/licenses/by/4.0/

(c) () D Den Access

\section{Abstract}

Introduction: Uterine malformation in general population is around $7 \%$ - $8 \%$. Abnormal fusion of the para-mesonephric duct (mullerian duct) during embryonic life results in a variety of congenital uterine malformations, such as uterus didelphys, uterus bicornis bicollis, uterus bicornis unicollis, uterus subseptae, uterus arcuatus, uterus unicornis. The bicornuate uterus accounts for approximately $10 \%$ of the mullerian anomalies. Women with bicornuate uterus have no extra uterine infertility issues. The uterine malformations are known to be associated with spontaneous miscarriages, intrauterine growth restriction, preterm deliveries, preterm prelabour rupture of membranes, breech presentation and increased rate of caesarean delivery. The rates of spontaneous abortion and premature delivery have been reported to reflect the degree of non fusion of the horns. The common complications and adverse reproductive outcomes associated with bicornuate uterus are recurrent pregnancy loss $(25 \%)$, preterm birth $(15 \%-25 \%)$ and cervical insufficiency $(38 \%)$. We reported a case of bicornuate unicollis pregnancy which was infertility treated and carried till 38 weeks and had a good outcome. Case Report: A 32-year-old nullipara presented to Infertility OPD at NIMS Medical College and Hospital with the chief complaint of inability to conceive in spite of having regular sexual intercourse for 12 years without using any contraception. Patient was then investigated, bicornuate uterus identified. Infertility treatment was done by Intrauterine Insemination (IUI). Patient conceived and pregnancy continued till term uneventfully. Discussion: The prevalence of uterine anomalies is $7 \%$ - $8 \%$. And now because of better availability of diagnostic modalities, better detection of such anomalies is possible. Bicornuate uterus is a congenital uterine anomaly that results from defective lateral fusion of the paramesonephric ducts at about the tenth week of intrauterine life around the fundus. A bicornuate uterus consists of two symmetric cornua that are fused caudad, with communication of the endometrial cavities-most often at the level of the uterine isthmus. In a partial bicornuate unicollis uterus the in- 
tervening cleft is of variable length. Bicornuate uterus has been reported to have the highest prevalence of cervical incompetence among mullerian anomalies. Prophylactic placement of cervical cerclage in selected patients has been reported to increase fetal survival rates.

\section{Keywords}

\section{Bicornuate Uterus, Paramesonephric, Mullerian Duct}

\section{Introduction}

Uterine malformation in general population is around 7\% - 8\% [1]. Abnormal fusion of the para-mesonephric duct (mullerian duct) during embryonic life results in a variety of congenital uterine malformations, such as uterus didelphys, uterus bicornis bicollis, uterus bicornis unicollis, uterus subseptae, uterus arcuatus, uterus unicornis. The bicornuate uterus accounts for approximately $10 \%$ of the mullerian anomalies. Women with bicornuate uterus have no extra uterine infertility issues [1]. The uterine malformations are known to be associated with spontaneous miscarriages, intrauterine growth restriction, preterm deliveries, preterm pre-labour rupture of membranes, breech presentation and increased rate of caesarean delivery. The rates of spontaneous abortion and premature delivery have been reported to reflect the degree of non fusion of the horns. The common complications and adverse reproductive outcomes associated with bicornuate uterus are recurrent pregnancy loss (25\%) [1] [2], preterm birth (15\% - 25\%) [3] and cervical insufficiency (38\%) [4]. We report a case of bicornuate unicollis pregnancy which was infertility treated and carried till 38 weeks and had a good outcome.

\section{Case Report}

A 32-year-old nullipara presented to Infertility OPD at NIMS Medical College and Hospital with the chief complain of inability to conceive inspite of having regular sexual intercourse for 12 years without using any contraception. Also complained of excessive bleeding during menstruation along with dysmenorrhoea.

GENERAL EXAMINATION: Patient was conscious, cooperative, well oriented.

GYNAECOLOGICAL EXAMINATION: Breast-tanner stage 5, no galactorrhoea, axillary and pubic hair tanner stage 5

Per speculum and per vaginum reveals no significant abnormality.

INVESTIGATIONS: Ultrasonography_-2d USG shows bicornuate uterus with hypoplastic left cavity and normal right cavity with ovaries normal size (Figure 1).

Hystrosalphingography showed bicornuate unicollis uterus with both patent fallopian tubes (Figure 2).

HORMONAL INVESTIGATION—Bld grp-O+ve, RBS— $86 \mathrm{mg} / \mathrm{dl}$, Serum LH—5.6 mIU/ml, FSH—10.4 $\mathrm{mIU} / \mathrm{ml}, \mathrm{TSH}-2.5 \mathrm{ng} / \mathrm{ml}, \mathrm{AMH}-2 \mathrm{ng} / \mathrm{ml}, \mathrm{PRL}-12.5 \mathrm{ng} / \mathrm{ml}$.

Husband Semen Examination—40 million, 20\% motility grade 1, no abnormal forms and pus cells.

Diagnostic hysteroscopy: uterine cavity divided into two with one cervi. Right cavity is normal with hypoplastic left cavity.

Diagnostic laproscopy: Uterus seen bicornuate with normal ovaries and bilateral chromopertubation positive, POD clear, no adhesions.

MANAGMENT: Explaining all consequences to patient, counselled for IUI or IVF surrogacy. She chose IUI and was called on day 3 of menstruation for ovulation induction by clomphene citrate. Regular serial follicular monitoring done from tenth day until $18 \mathrm{~mm}$ follicle seen, IUI performed. She turned UPT positive in the second cycle.

Patient was advised bed rest, luteal phase support given for 12 weeks and was on regular antenatal visits with regular ultrasonography, tetanus toxoids and routine medications. At 37 weeks she underwent elective caesarean section.

Intra operative findings: Bicornuate uterus with pregnancy in well developed right horn seen (Figure 3, Figure 4). Left horn measures $10 \times 12$ centimeters. A live female child weighing 2.4 kilograms was delivered. Placenta was located posteriorly in upper segment of right horn. The findings were confirmed by exteriorizing the uterus and noting the communication between the two cavities and single cervix. The patient had an 


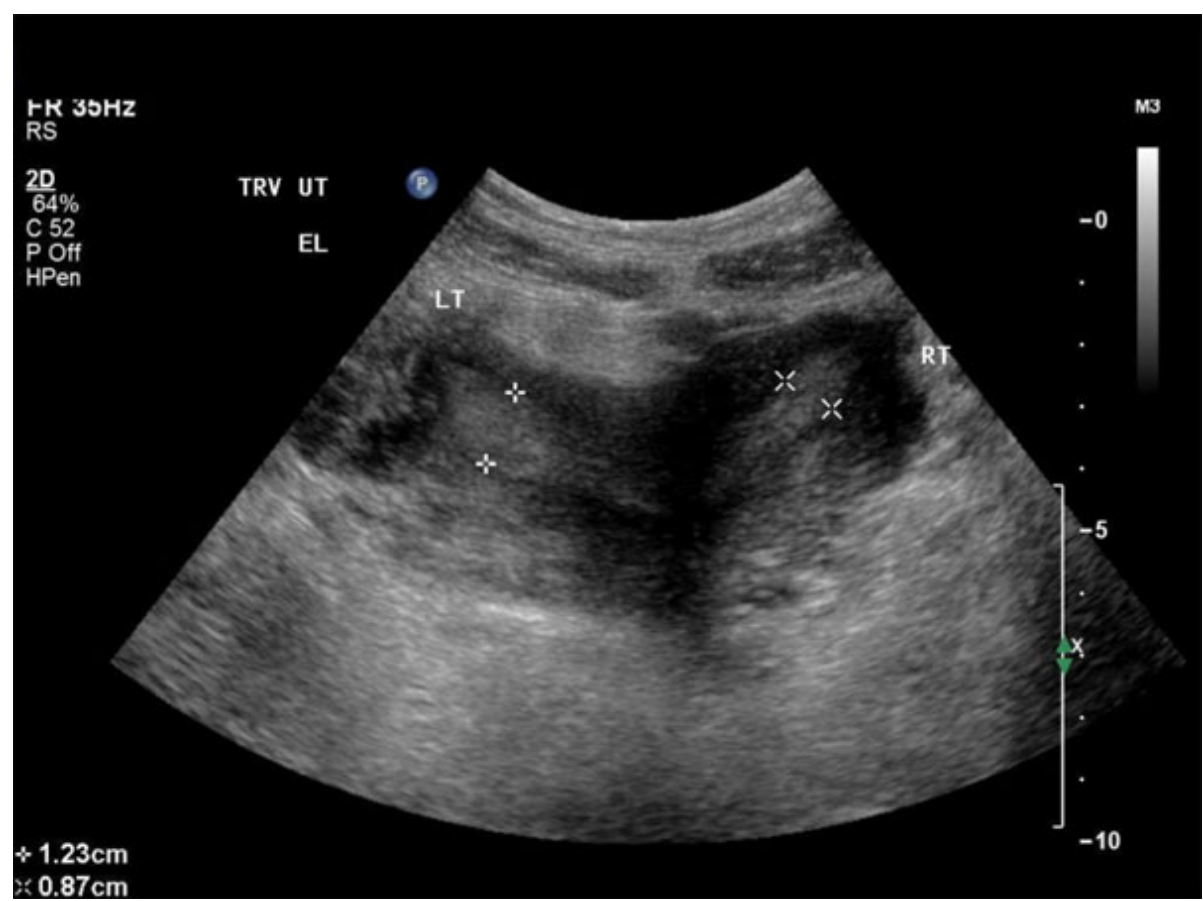

Figure 1. 2D USG scan showing bicornuate uterus.

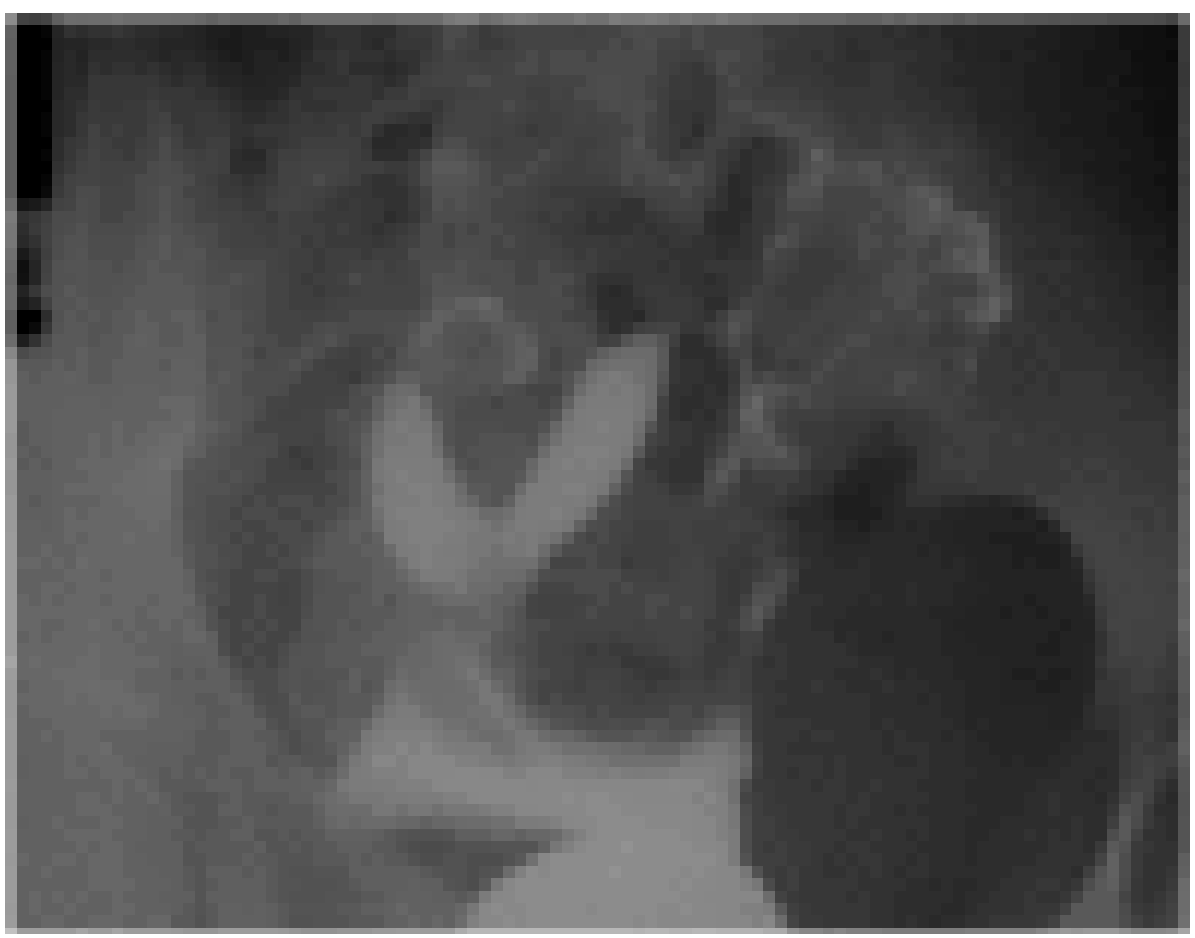

Figure 2. HSG Film showing biconuate uterus with bilateral patent fallopian tubes.

uneventful post operative period and discharged on 7th post operative period.

\section{Discussion}

The prevalence of uterine anomalies is $7 \%-8 \%$ [1]. And now because of better availability of diagnostic 


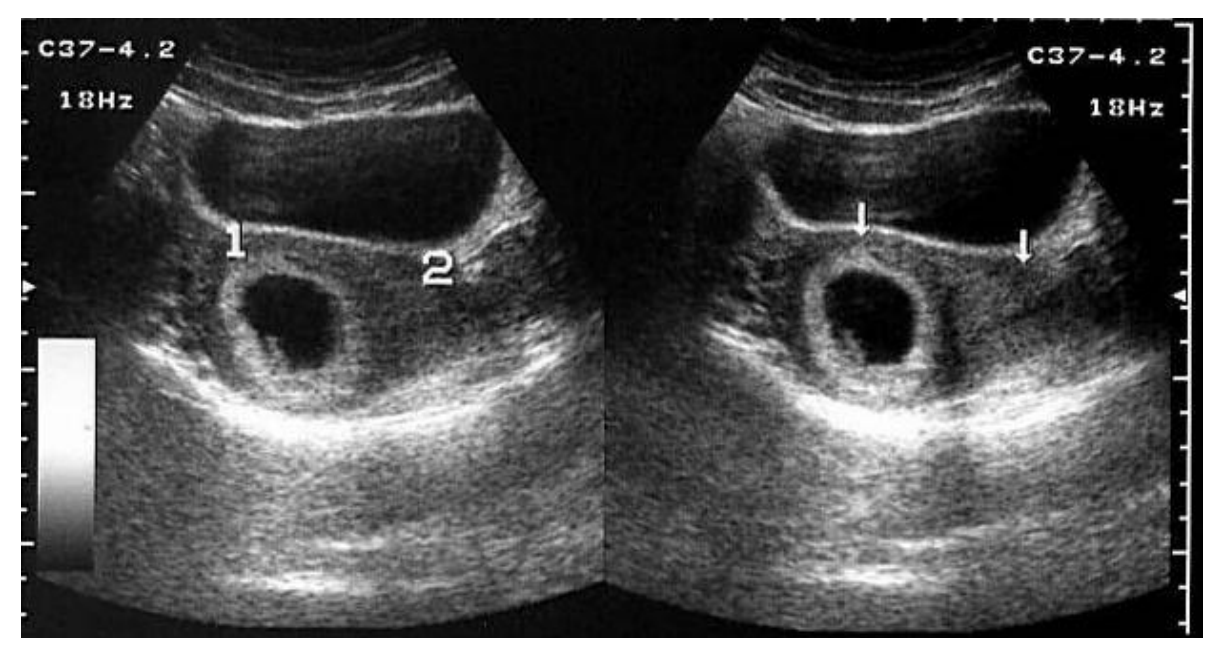

Figure 3. Early pregnancy in right horn of bicornuate uterus.1. right horn , 2. Left horn.

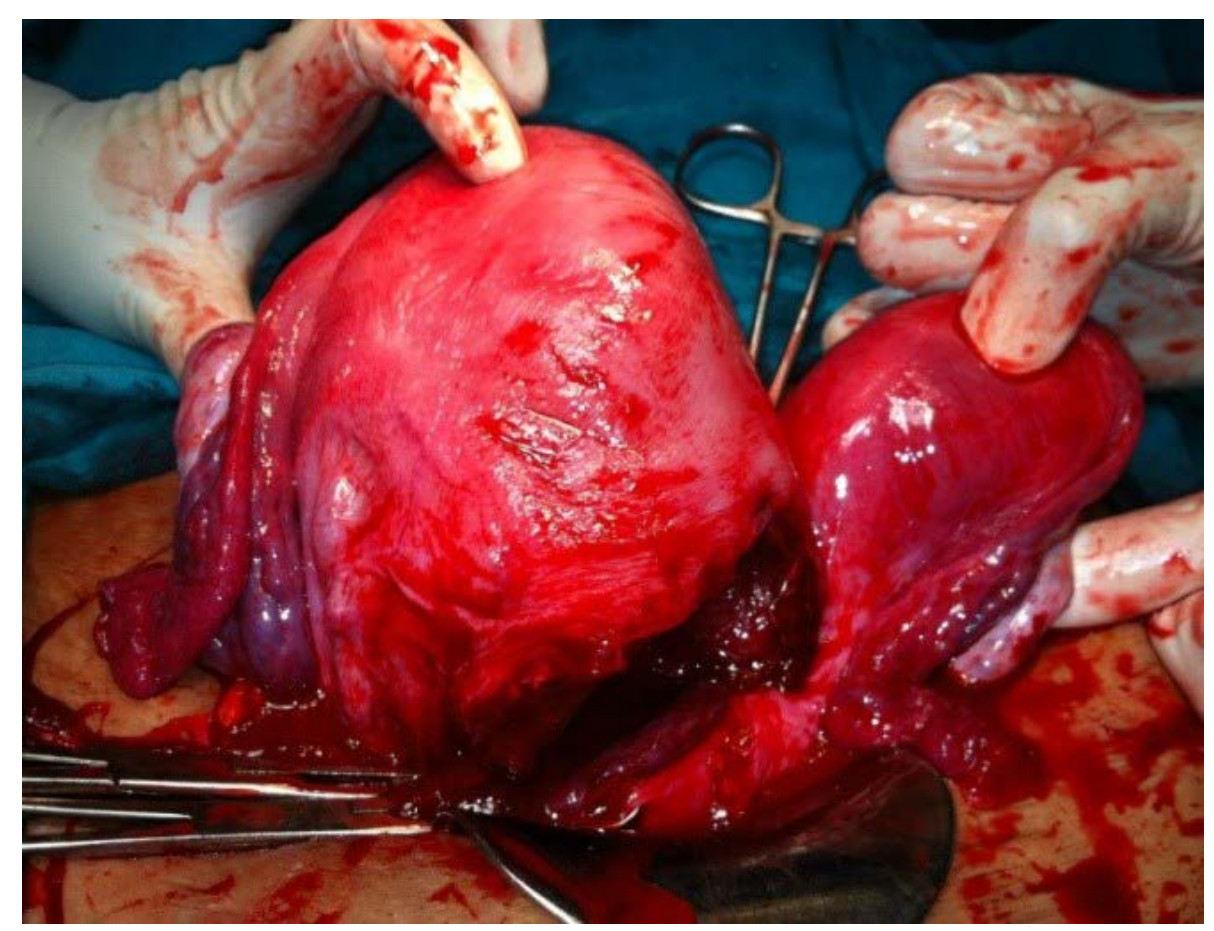

Figure 4. Showing intraoperative bicornuate uterus.

modalities, better detection of such anomalies is possible. Bicornuate uterus is a congenital uterine anomaly that results from defective lateral fusion of the paramesonephric ducts at about the tenth week of intrauterine life around the fundus. A bicornuate uterus consists of two symmetric cornua that are fused caudad, with communication of the endometrial cavities - most often at the level of the uterine isthmus. In a partial bicornuate unicollis uterus the intervening cleft is of variable length. Bicornuate uterus has been reported to have the highest prevalence of cervical incompetence among mullerian anomalies [4]. Prophylactic placement of cervical cerclage in selected patients has been reported to increase fetal survival rates [5]. Most widely accepted classification was given by subcommittee of the American fertility society (now the American society of reprooductive medicine) in 1986. Bicornuate uteri belong to class 4 Bicornuate Uterus with Successful Pregnancy Outcome www.iosrjournals.org 53|Page of this classification. Toaff et al. described nine subtypes of septate and bicornuate uteri with communicating cavities [6] [7]. 


\section{References}

[1] Lin, P.C. (2004) Reproductive Outcomes in Women with Uterine Anomalies. Journal of Women's Health (Larchmt), 13, 33-39. http://dx.doi.org/10.1089/154099904322836438

[2] Simon, C., Martinex, I., Pardo, F., Tartajada, M. and Iellicor, A. (1991) Mullerian Defects in Women with Normal Reproductive Outcome. Fertility and Sterility, 56, 1192-1193.

[3] Heinonen, P.K., Saarikoski, S. and Pystynen, P. (1982) Reproductive Performance of Women with Uterine Anomalies. An Evaluation of 182 Cases. Acta Obstetricia et Gynecologica Scandinavica, 61, 157-162. http://dx.doi.org/10.3109/00016348209156548

[4] Golan, A., Langer, R., Wexler, S., Seceg, E., Niv, D. and Menachem, P.D. (1990) Cervical Cerclage-Its Role in the Pregnant Anomalous Uterus. International Journal of Fertility, 35, 164-170.

[5] Blum, M. (1977) Prevention of Spontaneous Abortion by Cervical Suture of the Malformed Uterus. International Surgery, 62, 213-215.

[6] The American Fertility Society Classifications of Adnexal Adhesions, Distal Tubal Obstruction, Tubal Occlusion Secondary to Tubal Ligation, Tubal Pregnancies, Mullerian Anomalies and Intrauterine Adhesions. (1988) Fertility and Sterility, 49, 944-955.

[7] Toaff, M.E., Lev-Toaff, A.S. and Toaff, R. (1984) Communicating Uteri: Review and Classification with Introduction of Two Previously Reported Types. Fertility and Sterility, 41, 661-679. 
Scientific Research Publishing (SCIRP) is one of the largest Open Access journal publishers. It is currently publishing more than 200 open access, online, peer-reviewed journals covering a wide range of academic disciplines. SCIRP serves the worldwide academic communities and contributes to the progress and application of science with its publication.

Other selected journals from SCIRP are listed as below. Submit your manuscript to us via either submit@scirp.org or Online Submission Portal.
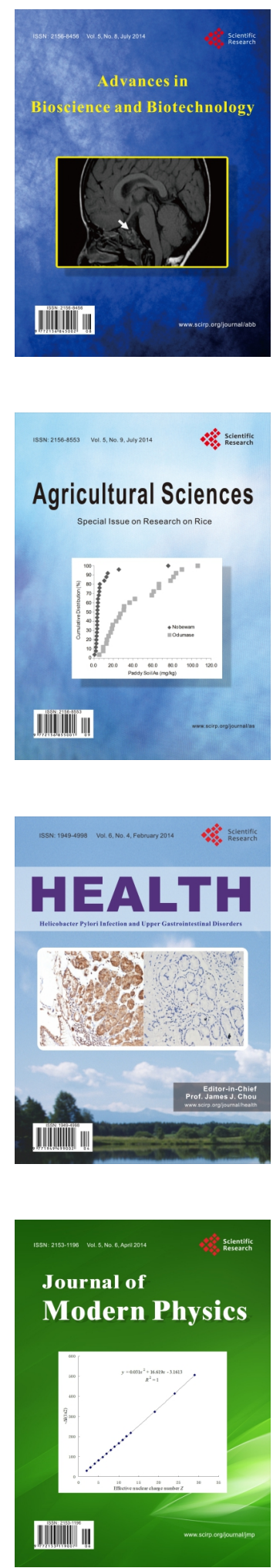
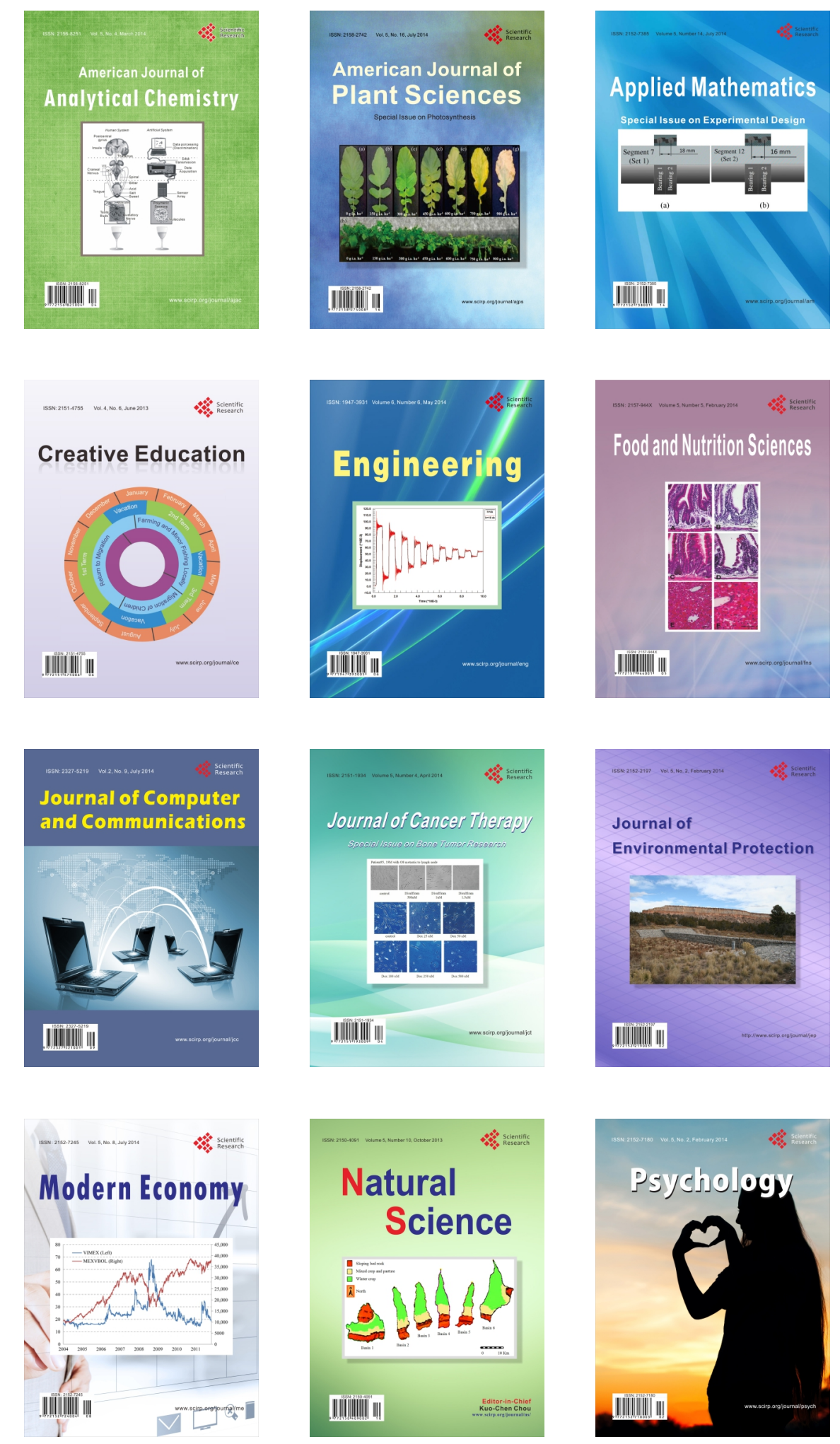